Vol. 4, Issue.6, Nov-Dec 2021, page no. 312-320

To cite this article: Thi Ngoc Thuy Doan, Huu Hao Nguyen and Tran Kieu Van Nguyen (2021). THE IMPORTANCE OF KNOWLEDGE MANAGEMENT IN ORGANIZATIONS: AN APPLICATION OF SECI MODEL AND SUGGESTIONS FOR VIETNAMESE ENTERPRISES, International Journal of Education and Social Science Research (IJESSR) 4 (6): 312-320

\title{
THE IMPORTANCE OF KNOWLEDGE MANAGEMENT IN ORGANIZATIONS: AN APPLICATION OF SECI MODEL AND SUGGESTIONS FOR VIETNAMESE ENTERPRISES
}

\author{
Thi Ngoc Thuy Doan', Huu Hao Nguyen ${ }^{2}$ and Tran Kieu Van Nguyen ${ }^{3}$ \\ ${ }^{1}$ Faculty of Economics and Business, Hoa Sen University, \\ 08 Nguyen Van Trang, Ben Thanh Ward, District 1, Ho Chi Minh City, Vietnam \\ ${ }^{2}$ Faculty of Economics and Business, Hoa Sen University, \\ 08 Nguyen Van Trang, Ben Thanh Ward, District 1, Ho Chi Minh City, Vietnam \\ ${ }^{3}$ Faculty of Economics and Business, Hoa Sen University, \\ 08 Nguyen Van Trang, Ben Thanh Ward, District 1, Ho Chi Minh City, Vietnam \\ DOI: http://dx.doi.org/10.37500/IJESSR.2021.4623
}

\begin{abstract}
Nowadays society, sciences, and technologies are developing strongly. Thus, knowledge is a necessity and plays an important role in every field, especially in business and production. Knowledge management creates an extremely effective and sustainable competitive advantage for businesses. In this article, we will introduce the framework of this knowledge creation process through the consideration of SECI's creative model, which illustrates the continuous transition between tacit knowledge and current knowledge. This article also provides some suggestions for Vietnamese businesses in the process of implementing knowledge-based management. This is also a topic that opens many opportunities for other research in Vietnam in the future.
\end{abstract}

KEYWORDS: Knowledge management, SECI model, Vietnam.

\section{INTRODUCTION}

In Asian developed countries such as Singapore, Japan, Korea, Taiwan, etc., knowledge management not only attracts in-depth research interest of a large number of academics in other countries but also from a practical perspective. Knowledge management has been applied comprehensively in many organizations and businesses in different fields. The success of corporations such as Honda, Toyota, Sony (Japan), Samsung, LG (Korea), HTC (Taiwan) has contributed significantly to the application of knowledge management in these corporations to create knowledge and creation of market-leading products. 
In Vietnam, managements and leaders of firms/organizations need to pay attention and focus on the application of knowledge in the process of administration, production, and business to create competitive and effective advantages for their businesses. In the trend of globalization, when competitive advantages are considered as a basic factor, the level of knowledge in each product, service, or operation will be a decisive factor that leads to the success or failure of the business.

The success of using knowledge as a tool to create a competitive advantage can be seen through the history of the "miraculous rise" of Japan or Israel, from resource-poor countries on the shore. In the realm of war, facilities have almost nothing; they immediately identify what they need - that is knowledge. Indeed, it is the knowledge that becomes the key for the two countries to have the success of today: good science and leaders in many fields and industries.

Many leaders recognize that the value of the business is in every good employee they have, not tangible production machines or large buildings. More precisely, the knowledge of each employee is the most important asset of an enterprise. Knowledge in this case is the understanding, personal techniques, and experience of personnel in work, partnerships. However, not all organizations capture the meaning of management to promote that intellectual property. This argument is not basic because the knowledge exists in an individual's recognization that throughout the process of individual receiving knowledge information that applying it by themself. The external effect cannot use that knowledge if the person does not want to share it. Making knowledge of human beings become an intellectual property and using good advantage for the common development of the organization that expects a mechanism, process of creating, sharing, and growing it in each organization. The role of the leader and manager is important to achieve this target. The manager always encourages and acknowledges knowledge information sharing and managers play a part in knowledge sharing actively. In another way, the manager should conduct employees to expand internal knowledge origins by way of the sharing group and internal seminars. This progression not only making improves individuals' knowledge but is also promoting motivation for continuous re and studying each employee.

The researcher and manager argue that to establish and hold on to the competitive advantage, a person's demand to use knowledge rather than traditional resources such as resources, capital, or land (Drucker, 1993). Hence, to accomplish the purpose, the manager, and business leader should base on knowledge management.

A group of Japanese strategic management scientists - headed by Nonaka - proposed a knowledgebased governance model in the 1990s or SECI model (Nonaka \& Takeuchi, 1995) to support managers to comprehend how to enlarge knowledge capital and share information knowledge in businesses. Therefore, managers apprehend the nature of knowledge-based governance and understand necessary to understand this model and apply it to organizations in Vietnam. 


\section{Literature review and theoretical framework}

In the field, research has many various determinations of knowledge. An argument that examined knowledge as a group includes experiences, advantages, communication, and deep understanding that also supported employees evaluate and grow new experiences and information (Davenport et al., 1998). Another study showed that knowledge is a combination of experience, advantages, and summary learning (Davenport et al., 1998). So, knowledge is contained in instruments and presented in conversations, procedures, rules, and exercises. Likewise, Bender and Fish (2000) determined that knowledge is real information, delineations, or talents gained across experience, training, or studying experience. As shown, many studies have various theories of knowledge, on another way all studies have the same establishment: knowledge covers information and skills which human beings gain. The knowledge and skills can keep in the sample of details, learning, knowledge gained from training, or experience gained from practice (Bender and Fish, 2000).

A study distributes knowledge to two types: implicit knowledge and explicit knowledge (Grant, 1996). In particular, knowledge is now discovered through transmission, and intangible knowledge is discovered through application search. For example, the language and patterns of communicative symbols, letters, and numbers are explicit knowledge. Tacit knowledge cannot be codified, it can only be observed through its application and acquired through experience. For example, employees can present others in the firm about their experience or implicit knowledge throughout their figure of speech, deductions, and real stories in life.

A study has shown that a firm's dynamic capability to incorporate knowledge tacit and explicit in the organization is the reason for firm innovation (Kogut and Zander, 1992). In the context of increasingly fierce competition today, the ability to collect, process and exploit information faster and more efficiently than competitors is how businesses create competitive advantages in the marketplace (Kogut and Zander, 1992).

Nonaka and Takeuchi (1995) were the first scholars to refer to the concept of "Knowledge-based governance", stemming from observing and analyzing how Japanese businesses grew successfully thanks to the process of promoting knowledge creation in all activities of the organization (Nonaka \& Takeuchi, 1995). Over the past three decades, this has become a research topic that has attracted the attention of a large number of international scholars and has been included in teaching content at leading business schools such as Harvard, Stanford, and MIT (Nonaka \& Takeuchi, 1995).

The term knowledge management was mentioned in the early 1980s but was not well received. It was not until the 1990s that the term became widely regarded and studied by scientists. However, to this day there is still no unified definition of knowledge management. As such, knowledge management is a broad concept. It has both a mechanical perspective (considering knowledge as an asset) and a bias 
toward social orientation (the knowledge created in an organization through social relations). The concepts raised in these studies are not the same but all share the following characteristics:

1. Knowledge management is a continuous process in creating, transferring, using, and protecting knowledge.

2. Knowledge management involves people and information technology in which people play a central role.

\section{SECI model and Some suggestions for Vietnamese organizations}

Administrators need to have a difference between knowledge management and information technology management (Gold et al., 2001). While information technology governance focuses on information collection and processing, it is less concerned with the process of creating knowledge management products and services, including both of the above: information collection and processing, innovative products, and services (Tseng \& Lee, 2014). Knowledge management focuses on the human element, while information technology is an important support factor for knowledge management (Gold et al., 2001; Tseng \& Lee, 2014; Zhang \& Huang, 2020).

Management: Focusing on gathering, organizing, and supporting knowledge (Nonaka model). A study has shown that knowledge in a company usually exists in two forms: tacit knowledge and explicit knowledge (Nonaka \& Takeuchi, 1995). If the organization's entire knowledge wallet is like an iceberg, then the visible part (text, media) is just like the tip of the iceberg (Nonaka \& Takeuchi, 1995). Meanwhile, most of the knowledge is implicit in each individual in the form of skills, know-how, experience (Nonaka \& Takeuchi, 1995). Thus, how to promote and spread this knowledge to enrich knowledge for the organization is an important issue.

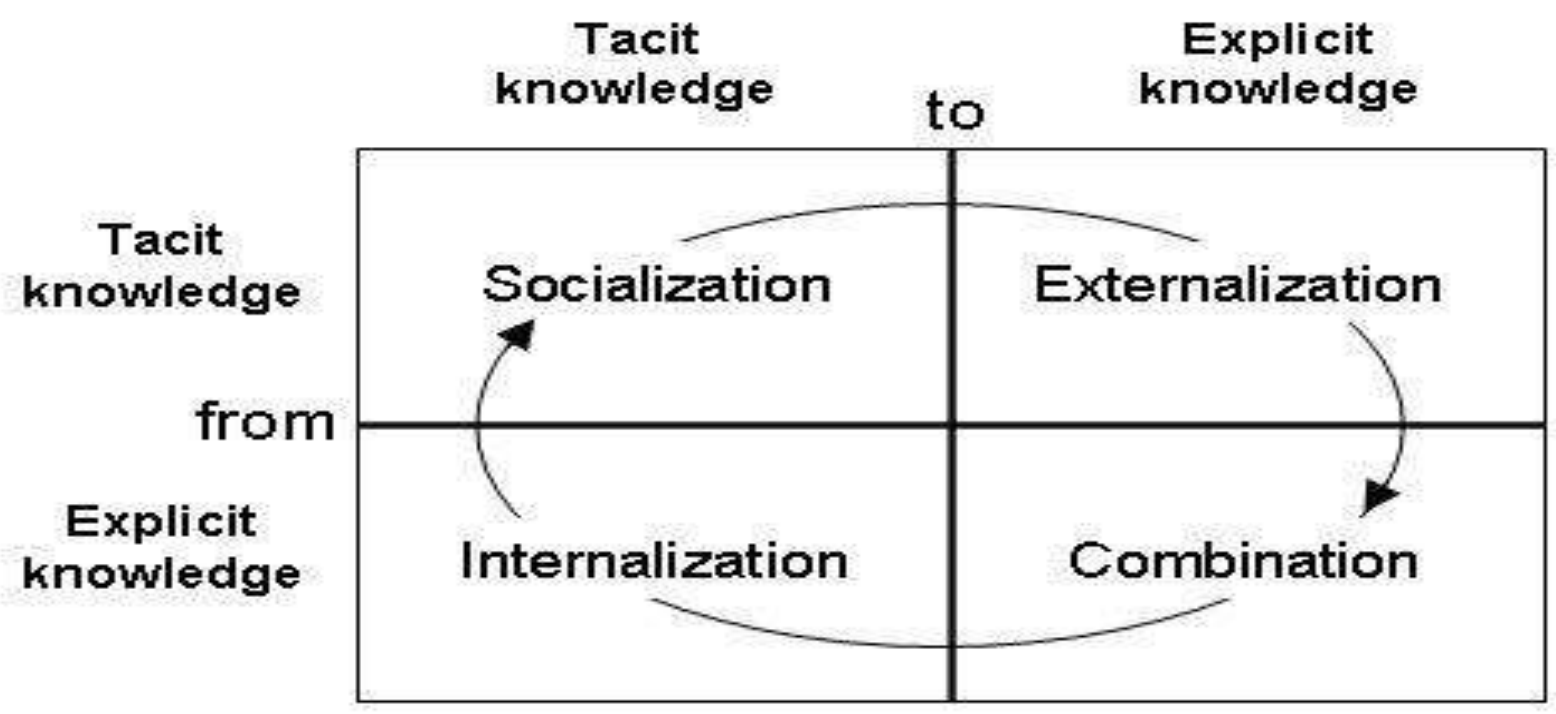

Figure 1: SECI model 
Application: Focusing on extracting and exploiting knowledge through advanced searches to perform required tasks.

Human: Referring to learning, sharing, and collaboration. This is an educational component of the cycle within the internal scope, moving into the socialization part.

SECI model - transforming knowledge forms in a spiral. SECI stands for four stages: Socialization, Externalization, Combination, and Internalization. These are, continuous steps in a stuck period to transfer tacit knowledge from one employee to another (S), from tacit knowledge to present form (E), from existing discrete knowledge to existing knowledge of higher quality $(\mathrm{C})$, and transforming existing knowledge into an individual (I). Based on an argument, the progress of constructing knowledge in enterprises is interactive progress and continual conversion between explicit knowledge and tacit knowledge (Nonaka \& Takeuchi, 1995). This progress happens in turn at various steps of knowledge: from personals, teams, firms to inter-organizations (Nonaka \& Takeuchi, 1995). This continual move forms an enlarging spire of knowledge, correlate with the increased proficiency of the firm (Nonaka \& Takeuchi, 1995). A attend of the knowledge transformation model of a study is that the spiral of knowledge building can start at any of the four steps introduced at the top (Nonaka \& Takeuchi, 1995). In summary, the performance of a firm is a rising cycle with no starting and no finishing (Nonaka \& Takeuchi, 1995) (Figure 1).

There are three general views in the knowledge management cycle that management, application, and business people need to apply (Andreeva \& Ikhilchik, 2011; Kahrens \& Früauff, 2018):

Management: Building culture, organizing, capturing, and creating knowledge. Communication is key to the changing management process within the enterprise, trust, and commitment, professionalism and accountability, transparency, and innovation. Data/information/knowledge becomes competitive for an organization, to increase competitiveness, businesses need to have good solutions through the effective exploitation of knowledge from each employee as well as the entire enterprise.

People: Learning, sharing, and distributing knowledge. Learning organization, rapid change in business operations: Products and services are always changing, exchanging, prices change daily, and the customer database is growing every minute - even every second. There is a need to update and share information about products, services, and customers continuously throughout the business.

Application: Search, discover, and apply knowledge. In the field of information technology today, there are many different tools, supporting the management and sharing of knowledge and experience among administrators and employees without geographical restrictions. 
Vol. 4, Issue.6, Nov-Dec 2021, p no. 312-320

In the process of socialization, individuals' tacit knowledge is shared as they experience it together in daily work interactions. In this phase, individuals capture and acquire knowledge in their working environment through action and awareness. For example, a person may share his or her tacit knowledge about customers, suppliers, or competitors with colleagues.

In the process of externalization, tacit knowledge gained from the socialization stage will be expressed as present knowledge. Tacit knowledge is shared collectively through language, images, models, or other expressions. Thereby, the tacit knowledge of individuals becomes more clear and easily absorbed by colleagues. For example, an experienced engineer describes the skills he/she possesses in materials used for internal training. Through externalization, businesses can impart these skills to new engineers or workers.

In the process of combination, explicit knowledge from the externalization phase will be arranged, combined, or processed to form a more complex and systematic existing knowledge system. Current knowledge is then disseminated to the entire organization. Specific examples of this phase are shown in the processes of translating product concepts into product-specific characteristics.

In the process of internalization, knowledge is now created and shared throughout the organization, after which it will be transformed into tacit knowledge according to each person's acquisition. For example, knowledge is currently a product concept. After being introduced in the organization, it must be realized through action, reflection, and practice to be absorbed into the knowledge of a person. Through this, the tacit knowledge of each individual is supplemented and absorbed. Later, tacit knowledge continues to be shared through the process of socialization, starting a new SECI process (Nonaka et al., 2000; Zaied et al., 2012).

The SECI model shows that knowledge is created in a continuous cycle through dialogue and practice. Dialogue is the basis of an effective knowledge creation process because it allows people to understand that there are different perspectives than their own, helping people accept and synthesize those views. This is an effective form of translating the inexpressible tacit knowledge into the official language of existing knowledge in the external phase of the SECI process. Dialogue through connecting, deepening, and refining existing knowledge will help create new existing knowledge in the combined phase of SECI (Nonaka et al., 2000) (Figure 2). 


\section{International Journal of Education and Social Science Research}

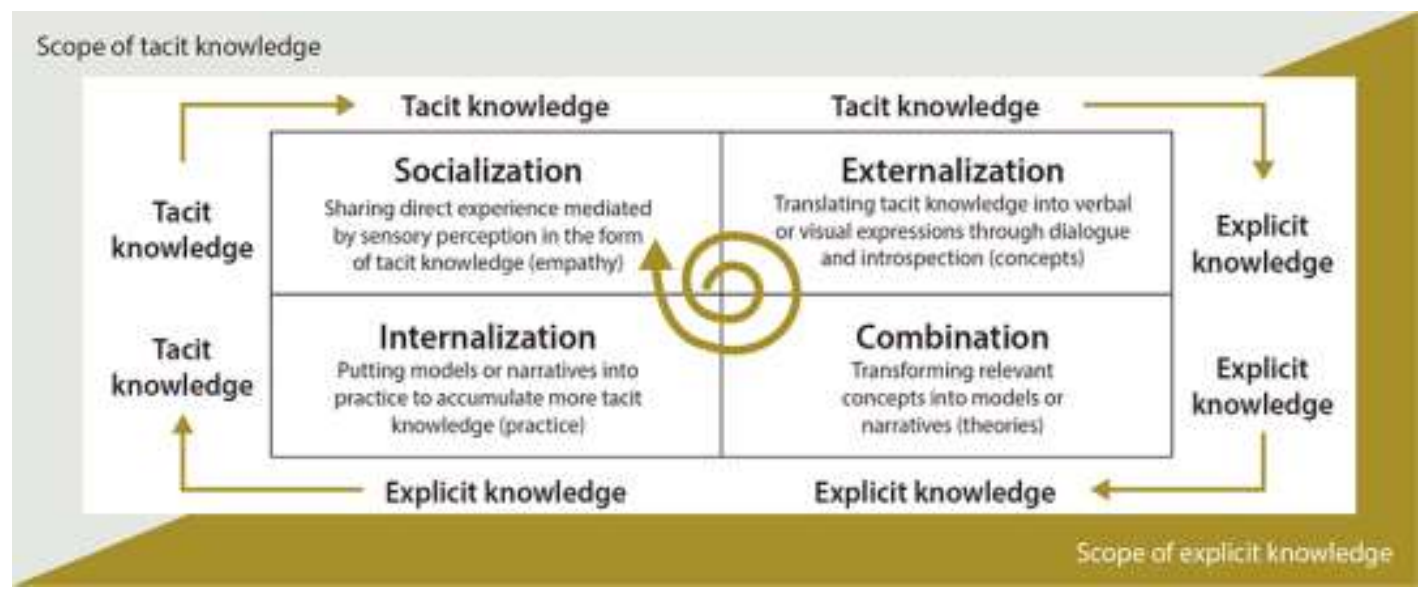

Figure 2: Scope of tacit knowledge and explicit knowledge

"What is the business achieving in the process of implementing knowledge management?" Capturing and creating knowledge, sharing, and distributing knowledge, searching, and applying knowledge are three issues that businesses are interested in, based on which business strategies are developed along with good knowledge management. Business executives need to do the following immediately to avoid falling behind in the development of the world economy in general and Vietnam in particular.

Knowledge management policies and procedures should be documented to avoid unnecessary misunderstandings and at the same time be easy to identify when mistakes occur.

Building a unified document system to capture knowledge. As mentioned above, one's knowledge is not easily conveyed to others. By demonstrating that knowledge through writing documents, exchanging, etc., the organization will improve the documentation system and the common knowledge database.

Focusing on training and knowledge transfer. Shared culture is essential in training activities. Experienced people should encourage and find themselves responsible for sharing and guiding less experienced people. Besides, an organization can take advantage of the knowledge of another organization if that knowledge is not used properly but must know how to protect its knowledge.

Constantly updated with new information and learning from the actions and experiences of other organizations.

Focusing on the human factor. People can create new knowledge and new people can apply that knowledge to continue to create new knowledge. The organization should have a policy of recruiting young human resources, enabling experienced people to work with new people, have appropriate remuneration, and always pay attention that a person's knowledge is inherently more than what he shows. 
Information technology applications. Finally, sharing activities, taking place effectively, are indispensable for the role of information technology. Information technology plays a supporting role, making it easier to share, store, update, and use knowledge. Moreover, continuous tectonic knowledge makes the knowledge of enterprises more and more huge, only information technology allows us to store, classify, update, share, use, and develop on time. Knowledge technology is an especially powerful implement in establishing an organization's database system/information system, permitting staff to serve conclusions at the right time and building a knowledge management network according to depth and width.

\section{CONCLUSION AND DISCUSSION}

The most difficult thing to implement knowledge management is probably the problem of awareness and recognition of knowledge as assets so that the managers have a sense of protecting, preserving, investing, and embellishing them into larger blocks of assets. Awareness is also in the corporate culture, in every employee of the business. By building the knowledge management system, it is not a project, it is a relentless accumulation of many individuals. So if the organizations do not start building knowledge management right now, maybe one day that business will become empty, poor, and failing machines in the marketplace.

In a globalized economy and knowledge, businesses will have to accommodate model positions to remain and develop. A lot of businesses have made huge fundings in technological renewal, goods, and services to be a competitor successfully in the Vietnam knowledge economy. In Vietnam, technological renewal and goods quality maintenance are regarded as the principal method to enhance competitiveness in the international market. Not long ago, more and more enterprises have understood that successful administration and capitalization on knowledge take a very important part in the sustainable development of enterprises over the world. So, we have given some suggestions to Vietnamese businesses in the process implement knowledge-based governance and also a topic that builds many chances for other future researchers in Vietnam.

\section{REFERENCES}

[1] Andreeva, T., \& Ikhilchik, I. (2011). Applicability of the SECI model of knowledge creation in Russian cultural context: Theoretical analysis. Knowledge and Process Management, 18(1), 56-66.

[2] Bender, S., \& Fish, A. (2000). The transfer of knowledge and the retention of expertise: the continuing need for global assignments. Journal of Knowledge Management.

[3] Davenport, T. H., De Long, D. W., \& Beers, M. C. (1998). Successful knowledge management projects. MIT Sloan Management Review, 39(2), 43.

[4] Drucker, P. (1993). Post-Capitalist Society. London: Butterworth Heinemann.

[5] Gold, A. H., Malhotra, A., \& Segars, A. H. (2001). Knowledge management: An organizational capabilities perspective. Journal of Management Information Systems, 18(1), 185-214. 
Vol. 4, Issue.6, Nov-Dec 2021, p no. 312-320

[6] Grant, R. M. (1996). Toward a knowledge-based theory of the firm. Strategic Management Journal, 17(S2), 109-122.

[7] Kahrens, M., \& Früauff, D. H. (2018). Critical Evaluation of Nonaka's SECI Model. In The Palgrave Handbook of Knowledge Management (pp. 53-83). Palgrave Macmillan, Cham.

[8] Kogut, B., \& Zander, U. (1992). Knowledge of the firm, combinative capabilities, and the replication of technology. Organization Science, 3(3), 383-397.

[9] Nonaka, I., \& Takeuchi, H. (1995). The knowledge-creating company: How Japanese companies create the dynamics of innovation. Oxford university press.

[10] Nonaka, I., Toyama, R., \& Konno, N. (2000). SECI, Ba and leadership: a unified model of dynamic knowledge creation. Long Range Planning, 33(1), 5-34.

[11] Tseng, S. M., \& Lee, P. S. (2014). The effect of knowledge management capability and dynamic capability on organizational performance. Journal of Enterprise Information Management.

[12] Zaied, A. N. H., Hussein, G. S., \& Hassan, M. M. (2012). The role of knowledge management in enhancing organizational performance. International Journal of Information Engineering and Electronic Business, 4(5), 27.

[13] Zhang, Z., \& Huang, F. (2020). An extended SECI model to incorporate interorganisational knowledge flows and open innovation. International Journal of Knowledge Management Studies, 11(4), 408-419. 